Retraction: Interleukin 17 acts in synergy with B cell-activating factor to influence B cell biology and the pathophysiology of systemic lupus erythematosus

Agnès Doreau, Alexandre Belot, Jérémy Bastid, Benjamin Riche, Marie-Claude Trescol-Biemont, Bruno Ranchin, Nicole Fabien, Pierre Cochat, Claire Pouteil-Noble, Pierre Trolliet, Isabelle Durieu, Jacques Tebib, Berhouz Kassai, Stéphane Ansieau, Alain Puisieux, Jean-François Eliaou \& Nathalie Bonnefoy-Bérard

Nat. Immunol. 10, 778-785 (2009); published online 31 May 2009; retracted 12 July 2013

Despite many attempts to replicate these results, the authors have been unable to confirm the original data showing that IL-17 alone or in combination with B cell-activating factor controls the survival of human B cells (Fig. 1a,b). Because this weakens the conclusions of the paper, all the authors (except A.D. and P.T., who could not be contacted) now retract this paper.

Corrigendum: The transcription factor IRF4 is essential for TCR affinitymediated metabolic programming and clonal expansion of $\mathrm{T}$ cells

Kevin Man, Maria Miasari, Wei Shi, Annie Xin, Darren C Henstridge, Simon Preston, Marc Pellegrini, Gabrielle T Belz, Gordon K Smyth, Mark A Febbraio, Stephen L Nutt \& Axel Kallies

Nat. Immunol. 14, 1155-1165 (2013); published online 22 September 2013; corrected after print 8 January 2014

In the version of this article initially published, the scale of the top row (Naive) for S1pr1 in Figure 5d is incorrect. With the correct scale, S1pr1 expression in naive CD8 ${ }^{+} \mathrm{T}$ cells is accurately presented as very high. The error has been corrected in the HTML and PDF versions of the article.

\title{
Corrigendum: Unifying immunology with informatics and multiscale biology
}

Brian A Kidd, Lauren A Peters, Eric E Schadt \& Joel T Dudley

Nat. Immunol. 15, 118-127 (2014); published online 21 January 2014; corrected after print 10 February 2014

In the version of this article initially published online, the URL provided for the analysis and visualization program FLOCK in Table 1 was incorrect. The correct link should be https://immport.niaid.nih.gov/immportWeb/analysis/flow/displayOverview.do?method=displayFlockOverview. The error has been corrected for the print, PDF and HTML versions of this article.

\section{Corrigendum: The transcriptional regulator Aire coopts the repressive ATF7ip-MBD1 complex for the induction of immunotolerance}

Michael Waterfield, Imran S Khan, Jessica T Cortez, Una Fan, Todd Metzger, Alexandra Greer, Kayla Fasano, Marc Martinez-Llordella, Joshua L Pollack, David J Erle, Maureen Su \& Mark S Anderson

Nat. Immunol. 15, 258-265 (2014); published online 26 January 2014; corrected after print 24 February 2014

In the version of this article initially published, the blot in the third row on the right in Figure 1c (Flag-Aire, 3\% input) was incorrect. The error has been corrected in the HTML and PDF versions of the article.

Corrigendum: $\mathrm{CD}^{+} \mathrm{T}$ cell lineage integrity is controlled by the histone deacetylases HDAC1 and HDAC2

Nicole Boucheron, Roland Tschismarov, Lisa Goeschl, Mirjam A Moser, Sabine Lagger, Shinya Sakaguchi, Mircea Winter, Florian Lenz, Dijana Vitko, Florian P Breitwieser, Lena Müller, Hammad Hassan, Keiryn L Bennett, Jacques Colinge, Wolfgang Schreiner, Takeshi Egawa, Ichiro Taniuchi, Patrick Matthias, Christian Seiser\& Wilfried Ellmeier Nat. Immunol. 15, 439-448 (2014); published online 30 March 2014; corrected after print 6 June 2014

In the version of this article initially published, Lisa Göschl's surname was spelled incorrectly. The error has been corrected in the HTML and PDF versions of the article. 